\title{
A Study on the Key Technology of Education Information Cloud Service Platform Integration
}

\author{
Yuan Linlin ${ }^{1, a}$, Zhou Guixian ${ }^{2, b^{*}}$,Qin $\operatorname{Jin}^{3, c}$ \\ ${ }^{1}$ Guizhou Vocational Technical Institute, Guiyang 550023,Guizhou,China \\ ${ }^{2}$ Information Institute GuiZhou College of Financial and Economic, Guiyang 550004, China \\ ${ }^{3}$ Computer Science and Technology GuiZhou University, Guiyang 550023, Guizhou,China \\ alinlinqizhi@qq.com, b120362538@qq.com, ${ }^{\mathrm{c}} 34067445 @ q q . c o m$
}

Keywords: education information; cloud service platform; integration

Abstract. Along With the development of new technology, cloud computation has become a new computing model and new Internet application mode, which is developed based on grid calculation. The concept, definition, features, layer architecture and service mode of cloud computation are described. The problems of cloud computation are summarized to provide guidance to the future research.

\section{Introduction}

Since the concept of the cloud computing is put forward, many experts and scholars and related enterprises from different research Angle of view for the cloud computing definition is given, so as to make the definition of cloud computing has been more than hundred kinds of basically, cloud computing is based on virtual technology as the core technology, is driven with economies of scale, with high speed Internet as the carrier, by a large number of resource pool of computing resources to support, dynamically according to user's demand to provide virtualized, scalable and flexible information services. In cloud computing mode, all kinds of information services in accordance with the requirements for individual users demand scale and dynamically build, operation and maintenance, generally in the form of pay-as-you-go users pay for its use of resources. So, cloud computing can make factors mainly includes three aspects of content[1]:

(1) technical factors is made to support cloud computing technology, such as web technology, virtualization technology, programming model, global distributed storage technology, web services and service-oriented architecture billing management, etc.

(2) the economic factor is the commercialization of cloud computing to support, such as industrial structure clear, reasonable business model, etc.;

(3) policy factors is to guarantee the legality of the cloud computing service quality and society to support, such as all kinds of sound supervision system and the support of government policy.

The basic principle of cloud computing is: to take advantage of the local or remote distributed or cluster computers provide Internet users with a variety of computing and information services (such as computing, storage, software and hardware services). Cloud computing can connect the common server or PC form a cluster to take advantage of the super computer computing and storage capacity. Cloud computing is the advent of high-performance parallel computing is no longer patent scientists and professionals, network ordinary users can also through the cloud computing platform to get the benefits of parallel computing, distributed computing and convenience[2]. Users in the use of the resources of the cloud platform does not need to know where the real server, not to care about how cloud platform internal work, with a high speed Internet can use a variety of transparent computing and information resources. Using this technology, the network service providers can be dealt with in a few seconds, tens of millions or even billions of information to and "super computer" the same powerful performance of network application service. 


\section{THE LEVEL OF THE CLOUD SERVICES AND ARCHITECTURE}

1) the cloud service level

General component is the level of cloud services infrastructure layer, platform layer and software, the use of cloud services market access conditions from high to low. Currently, more and more company or enterprise can provide different levels of cloud Service resources, some manufacturers can also provide equipment at the same time, platform, Software, such as multi-level computing services, such as Google can provide cloud computing platform Service, and provide cloud computing services of application Software, Software Service layer Software as a Service (SaaS, Software as a Service) than the rise of cloud computing, it is a kind of Software architecture, its application is designed for network delivery, making it easy for users to hosting, deployment and access via the Internet, and Software vendors in the unified plan of the application Software on the server, the customer can according to their own needs and to the manufacturer's order through the Internet application services needed by his own. Software as a service (SaaS) application software service price is usually "turnkey" charges, will usually application software license fee, software maintenance and technical support as a user of the monthly rental fee unity. Software as a service (SaaS) is the best way to use advanced information technology to implement the informationization and method, especially for small and medium-sized enterprises. But at present, the development of the software as a service (SaaS) is not very desirable, is one of the main reason of software as a service (SaaS) provider concentrates too much on the development of application software, and the management of the network resources ability is insufficient, lead to waste a lot of money on buying a server and bandwidth on the infrastructure, such as it provides to the user's load, however, is still limited. Cloud computing provides a simple and efficient network and information resources management mechanism, can help the software as a service (SaaS) manufacturers for vast users with unimaginable all kinds of resources, software as a service (SaaS) supplier don't need to be on the server and bandwidth waste your any infrastructure investment, focus on software development and application of the specific services, so under the mode of cloud services, software as a service (SaaS) market access conditions to relatively low platform service layer.

Platform as a Service (PaaS, Platform as a Service) is above the cloud computing infrastructure to provide abstraction level services Platform, is all kinds of software Platform of the system operation, such as the development Platform, business deployment and application Platform, and so on. Platform as a service (PaaS) on the way to obtain hardware resources is transparent for users. Platform service Providers (PPS), the Platform will) including software and hardware, operating systems, software updates, system security and other application service hosting service content [i3a], most of the Platform provider is limited to a particular language and the corresponding integrated development environment (IDE), such as Google's App Engine support Python and corresponding ides. Because of the cloud computing platform service for users is blocked the use of the operating system, hardware and storage complexity, so there is a need for platform providers play good system began to send ability and certain information resource management ability, caused the platform service provider market access conditions is relatively high. With the development of science and technology, the accumulation of customers and customer requirements gradually increase, part of the software as a service provider also gradually began to through the way based on software as a service to the user to provide platform service. Such as Sales Force is based on Force.com SalesForce.Com software service engine, build a commercial application, mobile applications and web site application development platform. Infrastructure services layer Infrastructure as a Service Infrastructure Providers (IPS, proceeds will) manages a lot of computing and storage resources. Infrastructure providers (IPS) with resource virtualization technology realize segmentation and dynamic adjustment of these resources, can provide users or service provider to system resources. In order to guarantee the reliability of the service and infrastructure providers (IPS) design and deployment of the corresponding software are needed to manage these services. Because the infrastructure as a service is built on a composed of a lot of computing resources based on information resource pool, need a lot of upfront investment, so the infrastructure as a service market access conditions relative to the platform as a service. Now many of the infrastructure providers (IPS) are already has a large accumulation of 
the history of computing and storage resources. Too, for example, as the world's leading web hosting provider, since 1998 in the world has nine data center, management of more than 50000 servers.

2) the architecture of cloud services

For mentioned above three types of cloud computing services, the giants in the IT industry are put forward different cloud computing solutions, but so far there are no a unified standard of technical architecture[3]. This paper cited China's cloud computing website structure of cloud computing architecture. This architecture summed up the current international main characteristics of different solutions. Will be divided into physical layer, resource pool resources, management middleware layer and Service Oriented Architecture (SOA, Service - Oriented Architecture) to build four layers.

(1) physical resources layer: mainly including computer, memory, network, database and software facilities and hardware and software resources.

(2) resource pool is to all kinds of the same type of resources constitute a resource pool with a similar structure or structure, such as computing resources, storage resources pool, the network resource pool, pool data resource pool and software resource pool, and so on. Building is the main purpose of the resource pool in order to carry out effectively the physical resource integration and management.

(3) management middleware layer: is responsible for all kinds of resources of cloud computing management and task scheduling, for a variety of applications in order to make these resources to provide service for various applications safely effective, is a business model of the most important part of cloud computing. User management is to provide various types of user interaction structure, management, and to identify the user identity, and create a user program execution environment and use resources for billing, and other functions to the users; Security management is responsible for the security of cloud computing overall safety of all kinds of resources and facilities, including user authentication, access authorization, security audit, and comprehensive protection, etc.

(4) the construction of a service-oriented architecture (SOA) : build SOA layer for short, is to all kinds of resources in cloud computing standard web services, and into a service oriented architecture system of unified management and use, including the service interface specification, user registration, search, access, and building service work flow, etc.

\section{THE DESIGN AND REALIZATION OF THE PLATFORM}

Summary page displays Operation System list on the management platform, common operations, shortcuts, platform global hardware information and tips, alarm information, details are The module to statistic current global basic information. Users will be clear at a glance to the current platform host amount, processor, desktop, memory, terminals, storage, users etc, the global information visual display provides convenient, and directly veiw for administrator management.

Education Information Cloud Service Platform Integration: It contains all the functions of this platform, the user can through the feature list to choose the required functions to directly access, also can be folded this feature list for the streamline pattern.

OS-Easy E-VDI is a complete solution about Virtual Desktop Infrastructure which developed by Wuhan OS-Easy Cloud Computing Co., Ltd. OS-Easy E-VDI $;$ realized the separation of desktop applications and terminal equipment, the user's desktop environment centralized deployed in the data center, and running on the virtual machine in the server which in the data center. Users access the virtual desktop through the network and can get the same effect as using the local PC.

By the way of centralized administration, lets administrators have more effective control and management permissions than traditional PC, and can on-demand delivery corresponding desktop according to user's actual application scenarios. 
Table 1 product components information

\begin{tabular}{|c|c|}
\hline ITEMS & DESCRIPTION \\
\hline $\begin{array}{l}\text { Console node (ie: Master } \\
\text { control node) }\end{array}$ & $\begin{array}{l}\text { The virtualization software which deployed on the server, only need one set } \\
\text { server as the master control node, then can through the master control node to } \\
\text { manage the whole servers cluster. M eanwhile the master control node can also } \\
\text { create the virtual machines to provide to the users. }\end{array}$ \\
\hline Compute node & $\begin{array}{l}\text { The virtualization software which deployed on the server, based on the KVM to } \\
\text { provide the virtualization layer, virtualized the physical server CPU, memory, } \\
\text { storage, and network resources, able to assigns them to multi setsi virtual } \\
\text { machines. }\end{array}$ \\
\hline M anagement platform & $\begin{array}{l}\text { With single management view of } \mathrm{B} / \mathrm{S} \text { structure, any networked PC can access } \\
\text { virtual desktop management platform of the console node via the browser, to } \\
\text { achieve unified management of the server virtualization IT architecture and } \\
\text { virtual desktops. }\end{array}$ \\
\hline Client side & $\begin{array}{l}\text { Client program installed on the terminal device, used for connect to the virtual } \\
\text { desktopis program, currently supports Windows platform and Linux platform. }\end{array}$ \\
\hline
\end{tabular}

Through the course list can view and edit each classroom teaching corresponding desktop scheduling details Week times. After the time is reached, it can automatically activate the default desktop to facilitate teaching. When new classrooms need to select a network, IP terminals under all classrooms have to be in this segment.

\section{SUMMARY}

Now, Cloud computing is an industry revolution of IT industry, about cloud computing technology is also in the research and application of such as fire, such as tea, for the development of computer and Internet enterprises brings new opportunities and challenges, this paper introduces the concept, application and key technologies of cloud computing, laid a theoretical foundation for future related research, and put forward the education in higher vocational education teaching cloud platform, the integration of key technology and application has a good application value and research prospects.

\section{Acknowledgments}

This paper is supported by the Commissioned by the national Open University,number :G14A3602W; This paper is supported by the Guizhou institute of vocational and technical college vocational education subject, number:15GH04; and The National Natural Science Fund;NO:61562009, and The National Natural Science Fund;NO:61562009;and the Guizhou University to introduce talents research project NO:[2012]028

\section{References}

[1] Anthony Y. H. Liao,Chin-Hung Liao,Jui-Chun Chien. Cloud-Based E-Learning Assessment and Remedial Tutoring System: A Case Study of the Idioms Self-Study in Elementary School[J]. Journal of Electronic Science and Technology. 2013(02)

[2] Ya-Fen Chang,Jen-Ho Yang. Guest Editorial:Special Issue on Cloud Computing[J]. Journal of Electronic Science and Technology. 2013(02)

[3] Hui-Hsin Huang. Interpurchase Time of Customer Behavior in Cloud Computing[J]. Journal of Electronic Science and Technology. 2013(02) 